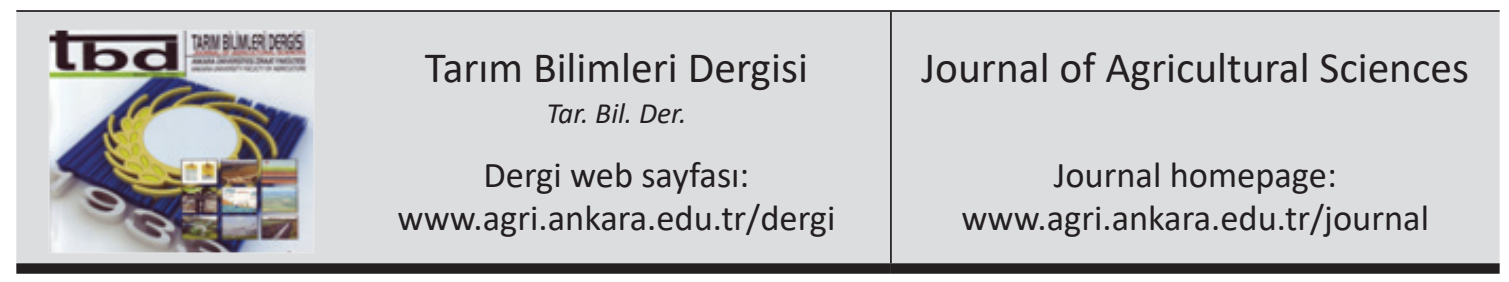

\title{
Numerical Investigation of Multiphase Transport Model for Hot-Air Drying of Food
}

\author{
Burak TURKAN ${ }^{\text {a }}$, Ahmet Serhan CANBOLAT ${ }^{\text {a }}$, Akin Burak ETEMOGLU ${ }^{\text {a }}$ \\ ${ }^{a}$ Bursa Uludag University, Faculty of Engineering, Mechanical Engineering Department, TR-16059, Bursa, TURKEY
}

\author{
ARTICLE INFO \\ Research Article \\ Corresponding Author: Burak TURKAN, E-mail: burakt@uludag.edu.tr, Tel: +90 (224) 2940745 \\ Received: 09 July 2018, Received in Revised Form: 03 November 2018, Accepted: 05 November 2018
}

\begin{abstract}
Drying is widely used to prevent microbial spoilage by evaporating the determined amount of liquid in the food sample. In order to reduce energy consumption and increase food flavor quality, modeling the drying process is crucial. In the literature, different approaches are used for investigation of drying characteristic. Among these approaches, the porous media approach have complex phenomena. Molecular diffusion for gases (water vapor and air), capillary diffusion for liquid (water), and convection mechanisms (Darcy flow) were used in drying model in porous media. In this study, firstly, the effect of shrinkage on drying of porous media was investigated. Non-linear partial differential equations for air and food material in the drying problem were solved numerically for non-steady state condition. The shrinkage effect in the drying process was studied by using the ALE (Arbitrary Lagrangian Eulerian) method. In this study, air velocities of $0.5,0.8$ and $1 \mathrm{~m} \mathrm{~s}^{-1}$, air temperatures of 40,50 and $60{ }^{\circ} \mathrm{C}$ and the geometric forms of rectangular, cylindrical and square were selected for hot air drying process. The fastest drying was obtained at square shape food at the air temperature of $60{ }^{\circ} \mathrm{C}$ and the air velocity of $0.5 \mathrm{~m} \mathrm{~s}^{-1}$. The analysis result showed that the air velocity and temperature have effect on the drying.
\end{abstract}

Keywords: Heat and mass transfer; Drying; Numerical modeling; Shrinkage

(C) Ankara Üniversitesi Ziraat Fakültesi

\section{Introduction}

The porous medium is a material containing pores filled with liquid and/or gas. Most of these pores are connected and so, the heat and mass transfer occur through these pores. A faster transport process occurs in pores, compared to the solid structure, in general. Many materials such as food products, soil, paper, stored grains can be defined as porous media. Heat and mass transfer processes in porous materials play an important role in the industry because of its product flavor quality, energy intensity, and process control requirements. There are different approaches in this field, which was investigated by numerous researchers either numerically or experimentally in the literature (Machado et al 1998; Sanjuan et al 1999; Datta 2007a). Drying of porous materials is an important process for food, textile, paper and pharmaceutical industry. The drying process assures the formation of simultaneous heat and mass transfer by applying hot air to the food product. Therefore, while the moisture content of the food decreases, its temperature value increases. Thus, it is ensured that food materials will last long without 
spoiling (Curcio et al 2008). The multiphase porous model helps efficiently identify the heat and mass transfer process, especially containing the internal evaporation mechanism, in food materials. During drying, water evaporation occurs inside and outside the material to be dried. The energy required for evaporation is provided by hot air in convective drying. In this case, the vapor and liquid phases formed within the material cannot be neglected. The mass transfer model formed for both phase states should be defined separately. During the drying of agricultural foods such as fruits and vegetables with high moisture content, a significant deformation effect is usually observed. The shrinkage effect, an observable phenomenon, has a strong effect on drying rate and food structure (Lima et al 2002). Defraeye et al (2016) used a neutron X-ray film to scan the moisture distribution in the food when drying fruit slices with forced convection. They examined the effects of air velocity, temperature, and radiation on the internal moisture distribution. Thus, mass transfer in food during the drying process has been visualized with the imaging technique used in their research. Ateeque et al (2014) developed a numerical model for estimating the moisture content of food material. The mass transfer was modeled as considering diffusion of liquid water from inner layer to outer surface of the food product followed by evaporation of water from the surface to the dry air which flows over the moist food product. Nguyen $\&$ Price (2007) examined the effect of experimental parameters such as temperature, moisture, and thickness in the drying of bananas. Yan et al (2008) investigated the effect of porosity, deformation and specific volume changes on the drying of banana, pineapple and mango with hot air. Ruhanian \& Movagharnejad (2016) experimentally examined the drying of thin potato layers in the infrared convective dryer. They performed their experiments with three different thicknesses and three different drying powers. It was also observed that almost all of the drying process occurred in the falling-rate period. It was found out that increasing the drying power reduced the moisture content and drying time and increased the deformation and effective moisture diffusion coefficient. The drying process is a complex and multivariable thermal process that should be investigated from different perspectives since the underlying physical mechanisms are still not perfectly understood. Therefore, in this study, a mathematical model was developed to calculate the moisture and temperature distribution of the food material inside the dryer. The multiphase transport model was developed for convective drying. Capillary diffusion was used for the liquid phase in the porous food material, and molecular diffusion and convection mechanisms were used for vapor. The effect of shrinkage rate was included in the model of heat and mass transfer for the prediction of moisture and temperature distributions during drying, with and without shrinkage rate cases. The obtained nonlinear unsteady-state partial differential equations were solved by Comsol Multiphysics 5.3. Thus, parameters affecting the drying process such as temperature, air velocity and geometric shape of the food were investigated. The main aim of this study was to predict the temperature and moisture distributions of different geometric shaped including rectangular, cylindrical and square food using multiphase transport model on convective drying process under different drying conditions (Inlet air velocity and air temperature).

\section{Material and Methods}

\subsection{Mathematical model}

The transfer mechanisms that occur in both the solid and the flow area were taken into consideration in developing the mathematical model for drying. While the liquid transfer was provided by the pressure and capillary pressure gradient in the solid, the vapor was transferred by the pressure and concentration difference as activation force. The pressure driven flow can be neglected because the amount of inner evaporation in forced convection drying is generally lower than that of microwave drying and vapor molecular diffusion model can be also used as a prevailing mechanism (Datta 2007a). The molecular diffusion for vapor flow and the capillary flow for liquid water flow are preferred. Mass transfer equations determined with liquid 
water and vapor for the porous media are given by Equation 1 and 2.

$$
\begin{aligned}
& \frac{\partial c_{w}}{\partial t}+\nabla\left(-D_{w} \nabla c_{w}\right)+u_{w} \nabla c_{w}=0 \\
& \frac{\partial c_{v}}{\partial t}+\nabla\left(-D_{v} \nabla c_{v}\right)+u_{v} v \nabla c_{v}=0
\end{aligned}
$$

Where $D_{w}$ is the capillary diffusivity in food, $D_{v}$ is the diffusion coefficient of vapor in food, $u_{v}$ and $u_{w}$ are the velocity of the water vapor and the velocity of liquid water within the solid, respectively. $c_{w}$ is the water concentration inside food, $c_{v}$ is the vapor concentration of the food (Bird et al 1960; Welty et al 2001). The equation between the water concentration $\left(c_{w}\right)$ and liquid phase saturation $\left(S_{w}\right)$ can be calculated as follows:

$$
S_{w}=\frac{c_{w} M_{w}}{\rho_{w} \varepsilon}
$$

Where; $M_{w}$ is the moisture content on wet basis, $\rho_{w}$ is the density of water and $\varepsilon$ is the porosity. In order to calculate this liquid phase velocity, the pressure gradient of the gas phase was taken into consideration. The liquid phase velocity is given by:

$u_{w}=-\frac{\kappa \kappa_{r l}}{S_{w} \varepsilon \mu_{w}} \nabla p_{g}$

Where; $\kappa_{r l}$ is the liquid phase permeability, $\kappa$ is the porous material permeability, $\nabla p_{g}$ is the pressure gradient, $\mu_{w}$ is the water viscosity (Datta 2007a). The liquid phase permeability is identified in Equation 5.

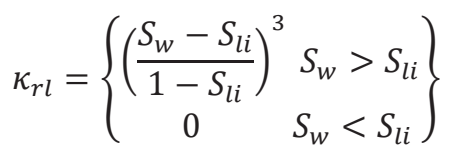

Where; $S_{l i}$ is the irreducible liquid phase saturation; this equation is used to identify the amount of liquid phase evaporation that remain in the porous material (Datta 2007b). The velocity field for the water vapor transfer calculated as follows:

$u=\frac{u_{g}}{S_{g} \varepsilon}-\frac{M_{a} D_{e f f}}{M_{m a} \rho_{m a}} \nabla \rho_{m a}$
Where; $M_{m a}$ is the molecular weight of the moist air $\left(\mathrm{kg} \mathrm{mol}^{-1}\right), \rho_{m a}$ is the density of the moist air, $D_{e f f}$ is the effective diffusion coefficient $\left(\mathrm{m}^{2} \mathrm{~s}^{-1}\right)$, $S_{g}$ gas phase saturation, $u_{g}$ is the flow field of moist air and $M_{a}$ is the molecular weight of air $\left(\mathrm{kg} \mathrm{mol}^{-1}\right)$. The effective diffusion coefficient is defined as:

$D_{e f f}=D_{v a} \varepsilon^{4 / 3} S_{g}{ }^{10 / 3}$

Where; $D_{v a}$ is the air-vapor diffusivity $\left(\mathrm{m}^{2} \mathrm{~s}^{-1}\right)$, the equation of continuity for the laminar flow field is given by Equation 8 and 9

$$
\begin{aligned}
& \rho \frac{\partial u}{\partial t}+\rho(u \nabla) u=\nabla\left[-p l+\mu\left(\nabla u+(\nabla u)^{T}\right)-\frac{2}{3} \mu(\nabla u) l\right] \\
& \frac{\partial P}{\partial t}+\nabla(\rho u)=0
\end{aligned}
$$

Where; $\rho$ is the air density $\left(\mathrm{kg} \mathrm{m}^{-3}\right), \rho$ is the pressure within drying tunnel $(\mathrm{Pa}), \mathrm{u}$ is the air velocity vector $\left(\mathrm{m} \mathrm{s}^{-1}\right)$. The energy equation for the drying air is given by Equation 10 (Bird et al 1960; Welty et al 2001; Comsol Multiphysics 5.3 2017).

$$
\rho c_{p} \frac{\partial T}{\partial t}+\rho c_{p} u \nabla T+\nabla q=0 \quad q=-k \nabla T
$$

Where; $\rho$ is the air density $\left(\mathrm{kg} \mathrm{m}^{-3}\right), c_{p}$ is the specific heat $\left(\mathrm{J} \mathrm{kg}^{-1} \mathrm{~K}^{-1}\right), k$ is the thermal conductivity $\left(\mathrm{W} \mathrm{m}^{-1} \mathrm{~K}^{-1}\right), q$ is the heat flux $\left(\mathrm{W} \mathrm{m}^{-2}\right)$ and $\mathrm{u}$ is the velocity vector $\left(\mathrm{m} \mathrm{s}^{-1}\right)$. The energy equation within the solid according to Fourier's law can be written as Equation 11.

$\frac{\partial T}{\partial t}+\rho c_{p} u \nabla T+\nabla q=0 \quad q=k_{e f f} \nabla T$

Where; $k_{\text {eff }}$ is the food effective thermal conductivity $\mathrm{W} \mathrm{m}^{-1} \mathrm{~K}^{-1}, \rho$ is the density of food $(\mathrm{kg}$ $\left.\mathrm{m}^{-3}\right), c_{p}$ is the specific heat $\left(\mathrm{J} \mathrm{kg}^{-1} \mathrm{~K}^{-1}\right)$ and $\mathrm{u}$ is the velocity vector $\left(\mathrm{m} \mathrm{s}^{-1}\right)$.

While the vapor transfer occurs in the air, the liquid water transfer does not occur. Mass transfer equations for the air were provided with convection and diffusion. The mass balance is given by Equation 12 (Bird et al 1960; Welty et al 2001; Comsol Multiphysics 5.3 2017). 
$\frac{\partial c_{a}}{\partial t}+\nabla\left(-D_{a} \nabla c_{a}\right)+u \nabla c_{a}=0$

Where $c_{a}$ is the water vapor concentration in the air and $D_{a}$ is the diffusion coefficient of water vapor in air $\left(\mathrm{m}^{2} \mathrm{~s}^{-1}\right)$ and $\mathrm{u}$ is the velocity vector $\left(\mathrm{m} \mathrm{s}^{-1}\right)$. It is difficult to calculate the shrinkage effect experimentally. Therefore, the shrinkage velocity should be estimated, to take into account the shrinkage in this study. The velocity value on the surface is given by Equation 13:

$u(b)=\frac{b-b(\text { old })}{\Delta t}$

Where; $b($ old $)$ is the half-thickness of the food at the next time, and $b$ is the half-thickness of drying material (Karim \& Hawlader 2005). The following expression can be used to calculate the half-thickness of the food at any time (Desmorieux \& Moyne 1992).

$b=b_{0}\left[\frac{\rho_{w}+M \rho_{s}}{\rho_{w}+M_{0} \rho_{s}}\right]$

Where $\rho_{w}$ is the water density $\left(\mathrm{kg} \mathrm{m}^{-3}\right), \rho_{s}$ is the food density $\left(\mathrm{kg} \mathrm{m}^{-3}\right)$ and $M_{0}$ is the initial moisture content $\left(\mathrm{kg} \mathrm{kg} \mathrm{dry}^{-1}\right), M$ is the moisture content $(\mathrm{kg}$ $\left.\mathrm{kg} \mathrm{dry}{ }^{-1}\right), b_{0}$ is the initial half-thickness. The fluid flow, heat transfer and transport phenomena should be considered during the drying process. It was assumed that porous media contains water vapor and liquid water. The flow area around the material in the tunnel was assumed laminar (Figure 1). Food material with different geometric shapes was modeled for numerical simulation. Mesh sizes used in the analysis affects the solution. Therefore, it is required to test grid independency (Sabarez 2012). Different mesh structures were applied to rectangle, cylinder and square food and air domains (Figure 2). The solution of grid independency was carried out with accuracy $1 \%$. Finally, for the accurate solution, grid structure of rectangle, cylinder and square which consists of 8868,8047 and 4745 elements was selected based on preliminary study, respectively. The time-dependent problem was solved by using an implicit time stepping method. The nonlinear PDE (partial differential equations) were solved using Newton's method with relative tolerance 0.001 and absolute tolerance 0.0001 using the commercial Comsol Multiphysics 5.3. Dimensions of the rectangular, the diameter of cylinder and the edge of the square used in the model were considered $1 \times 2.5$ $\mathrm{cm}, 1.2 \mathrm{~cm}$ and $1 \mathrm{~cm}$, respectively. The channel dimensions were $15 \mathrm{~cm}$ height and $40 \mathrm{~cm}$ width. The parameters and thermophysical properties used in the analyses are presented in Table 1. Non-linear partial differential transport equations were solved by the numerical method in order to determine the temperature and moisture content values of the air and food material. The deformed mesh was used to consider the volume change due to the fluid transfer. Therefore, an Arbitrary Lagrange Eulerian (ALE) was applied in the Comsol Multiphysics 5.3. The ALE method is used as an application between the Lagrangian and Eulerian approaches that allow the identification of moving boundaries. The Laplace smoothing type was defined as the deformed mesh.

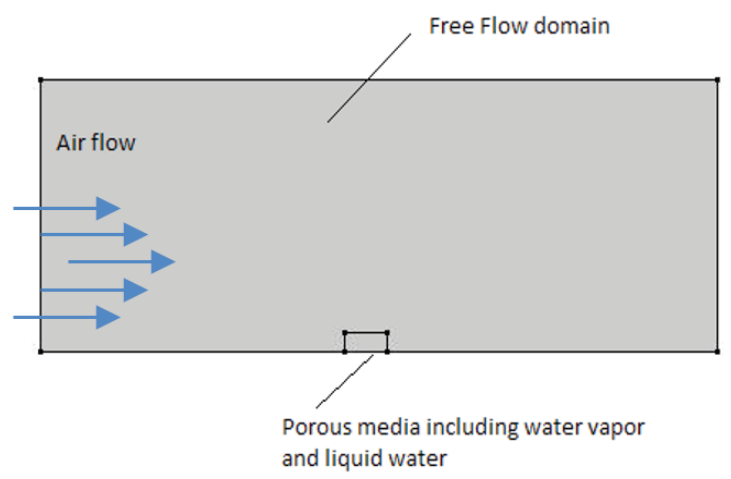

Figure 1- The model and flow field used in analyses

\subsection{Predicted models}

In order to determine the effect of the shape deformation, models with and without shrinkage were compared with the experimental results. The rectangular shape food was experimentally dried to observe the deformation effect on drying. Therefore, the experimental study should be performed. The numerical results were compared with experimental data in Figure 3. 


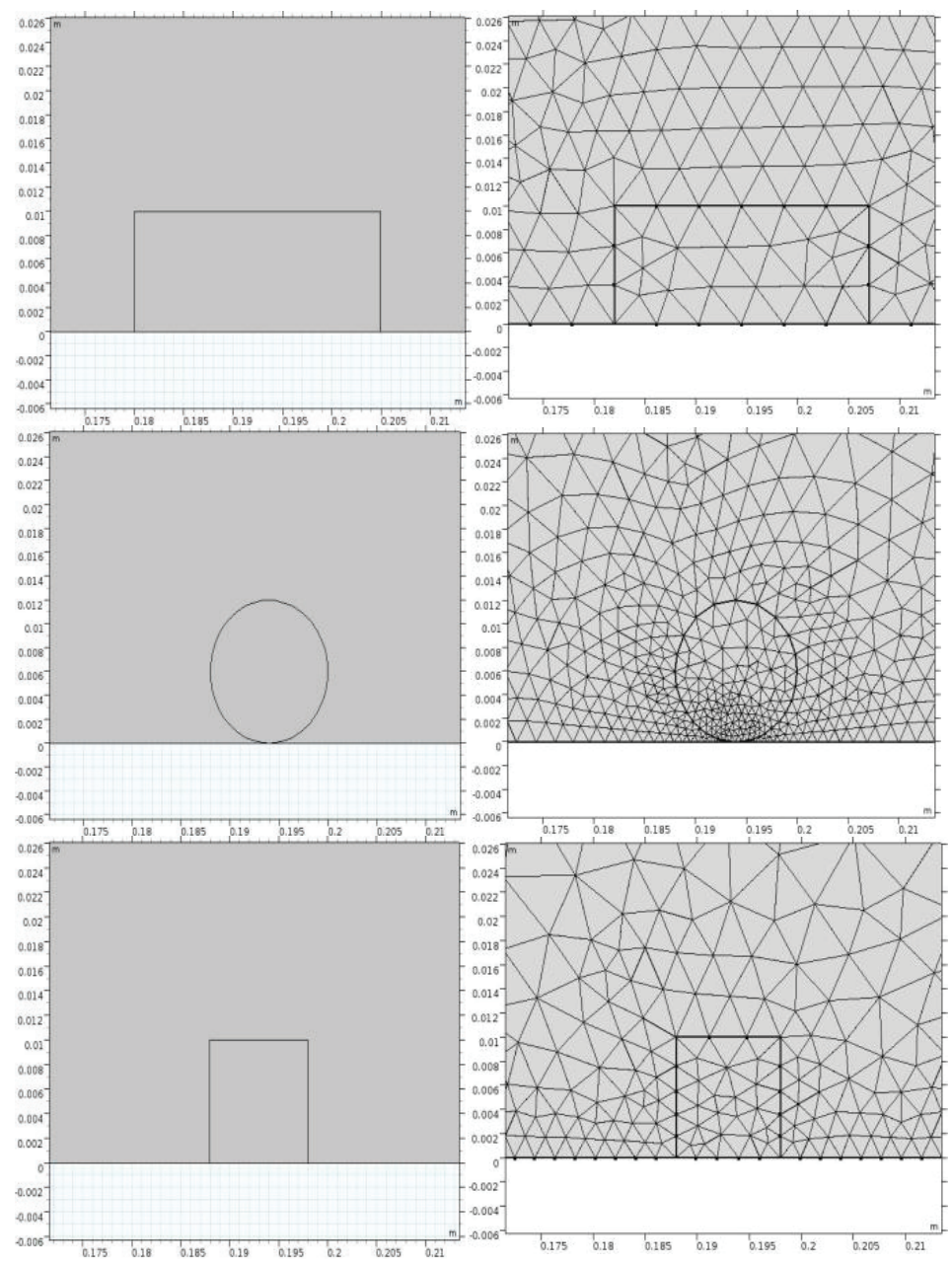

Figure 2- Rectangular, cylindrical and square shaped geometries and mesh structures

Table 1- Drying parameters and thermophysical properties of banana used in the model (Karim \& Hawlader 2005; Bart-Plange et al 2012)

\begin{tabular}{ll}
\hline Parameter & Value \\
\hline Air velocity $\left(\mathrm{m} \mathrm{s}^{-1}\right)$ & $0.5-0.8-1$ \\
Food temperature $\left({ }^{\circ} \mathrm{C}\right)$ & 21 \\
Food density $\left(\mathrm{kg} \mathrm{m}^{-3}\right)$ & 980 \\
Air temperature $\left({ }^{\circ} \mathrm{C}\right)$ & $40-50-60$ \\
Food initial moisture content $\left(\mathrm{g} \mathrm{g} \mathrm{dry}^{-1}\right)$ & 2.62 \\
Thermal conductivity of food $\left(\mathrm{W} \mathrm{m}^{-1} \mathrm{~K}^{-1}\right)$ & $0.006 \mathrm{M}+0.120$ \\
Specific heat of food $\left(\mathrm{J} \mathrm{kg}^{-1} \mathrm{~K}^{-1}\right)$ & $0.811 \mathrm{M}^{2}-24.75 \mathrm{M}+1742$ \\
Heat of vaporization $\left(\mathrm{kJ} \mathrm{kg}^{-1}\right)$ & $2383-2407-2359$ \\
Water density $\left(\mathrm{kg} \mathrm{m}^{-3}\right)$ & 0.018 \\
\hline
\end{tabular}

M, moisture content (g g dry $\left.{ }^{-1}\right)$ 

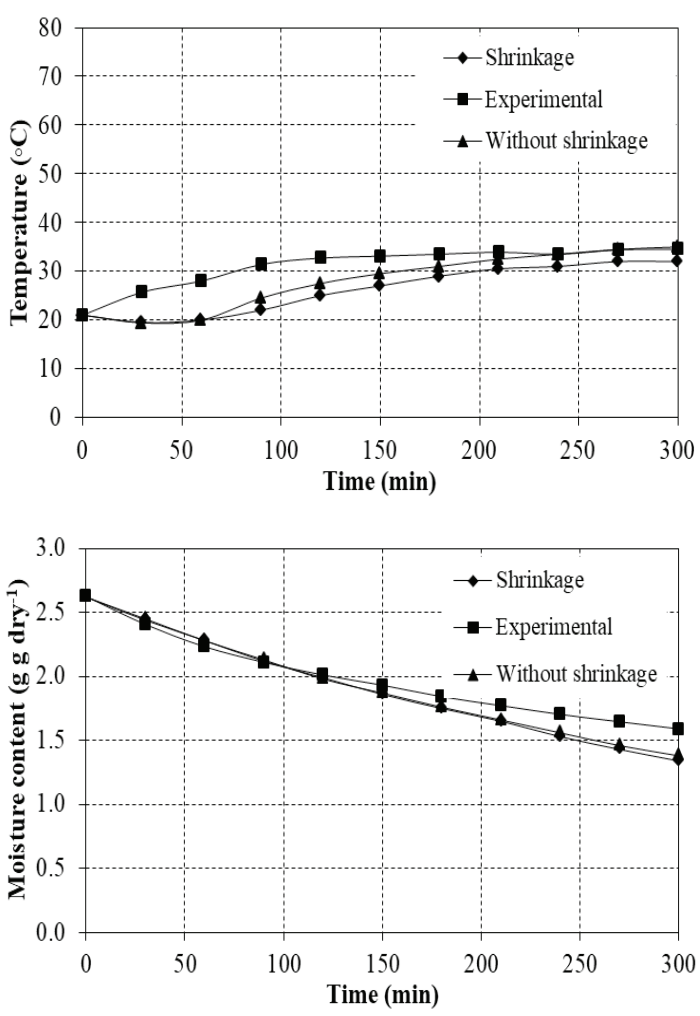

Figure 3- Variation of temperature and moisture content with/shrinkage and experimental study with drying time

\subsection{Test condition}

The drying characteristics at different air velocities $\left(0.5,0.8\right.$ and $\left.1 \mathrm{~m} \mathrm{~s}^{-1}\right)$ and temperatures $(40,50$ and $60^{\circ} \mathrm{C}$ ) for rectangular, cylindrical and square shaped food material (banana) were obtained.

\section{Results and Discussion}

The numerical results which were obtained from these two theoretical models (with and without shrinkage effect) were compared with the obtained experimental results. The numerical results of both models were found to be in good agreement with the obtained experimental results. $0.8 \%$ difference for moisture content and $6.2 \%$ difference in temperature between with and without shrinkage were found. Therefore, it was used in the analysis the theoretical model which is without shrinkage effect. Difference between the experimental and the analytical results can be explained by the constant thermophysical properties of the food in the calculations and difficulties in the experimental measurement (Liu $\&$ Cheng 1991). The dimension and moisture content changes of food due to shrinkage effects are presented in Figure 4. It was observed that the shrinkage effect exists with the evaporation in the food over time. It is difficult to determine the moisture distribution inside the food sample experimentally. Therefore, simulation can be used to calculate moisture distribution inside the material (Hussain \& Dincer 2003; Kumar et al 2015).

The center moisture content of the samples was obtained during drying. Figure 5 shows the predicted moisture contents calculated during the drying at different air velocities and geometric forms of food at $40{ }^{\circ} \mathrm{C}$. Air velocity affects the drying process. It is clear that increasing drying air inlet velocity increase drying rate (Karim \& Hawlader 2005; Aversa et al 2007; Curcio et al 2008). The squareshaped food material dried in a shorter time than the cylindrical and rectangular-shaped foods. At the end of the fifth hour, for the drying air velocity of $1 \mathrm{~m}$ $\mathrm{s}^{-1}$, while the moisture content was $1.06 \mathrm{~g} \mathrm{~g} \mathrm{dry}^{-1}$ in the rectangular shape, it was calculated to be 0.33 and $0.1 \mathrm{~g} \mathrm{~g} \mathrm{dry}^{-1}$ in cylinder and square, respectively. At the end of the fifth hour, the moisture content of square-shaped food was decreased by $28 \%$ for increasing air velocity from $0.5 \mathrm{~m} \mathrm{~s}^{-1}$ to $0.8 \mathrm{~m} \mathrm{~s}^{-1}$ and by $14 \%$ for increasing air velocity from $0.8 \mathrm{~m}$ $\mathrm{s}^{-1}$ to $1 \mathrm{~m} \mathrm{~s}^{-1}$. Figure 5 shows predicted variation of the temperature of food during drying at the air temperature of $40{ }^{\circ} \mathrm{C}$. The surface temperature values of rectangular, cylindrical and square shape food material were determined to be $38.2,37.5$ and $39.5^{\circ} \mathrm{C}$ after the five-hour period at the air velocity of $1 \mathrm{~m} \mathrm{~s}^{-1}$ (Figure 6). As the drying air velocity increased, the surface temperature of the food material increased (Curcio et al 2008). The result showed that the highest surface temperature was determined for the square-shaped food. Figure 7 shows the predicted moisture content of food at air velocity of $0.5 \mathrm{~m} \mathrm{~s}^{-1}$ for different air temperatures. 


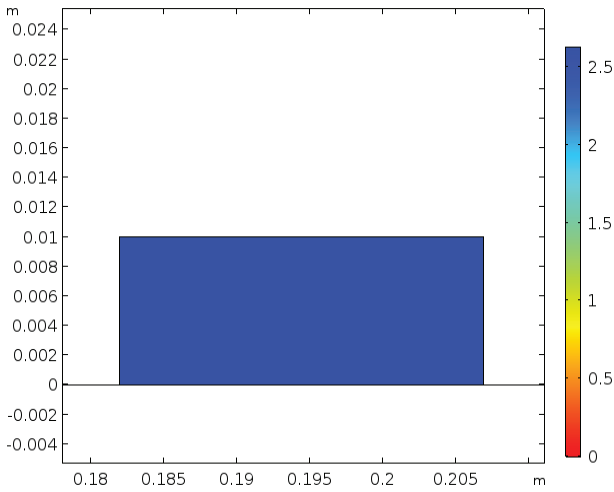

(a)

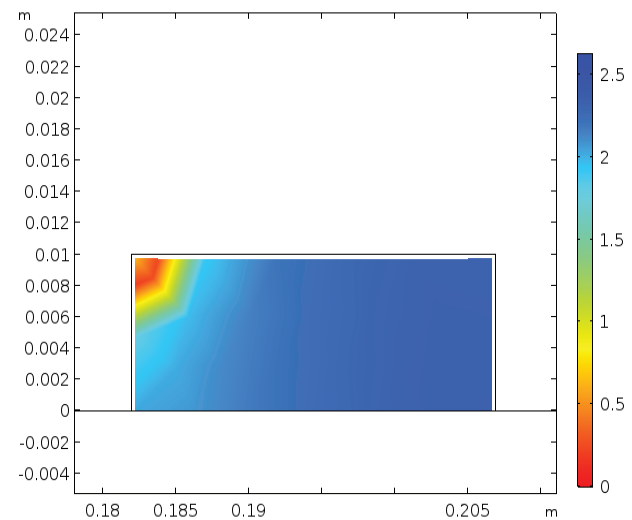

(b)

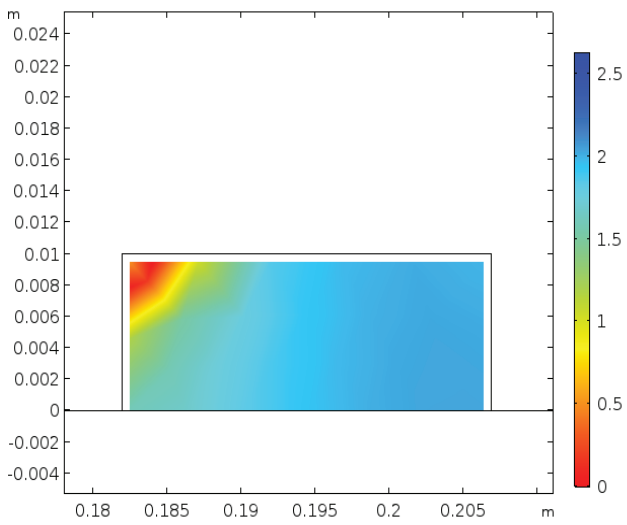

(c)

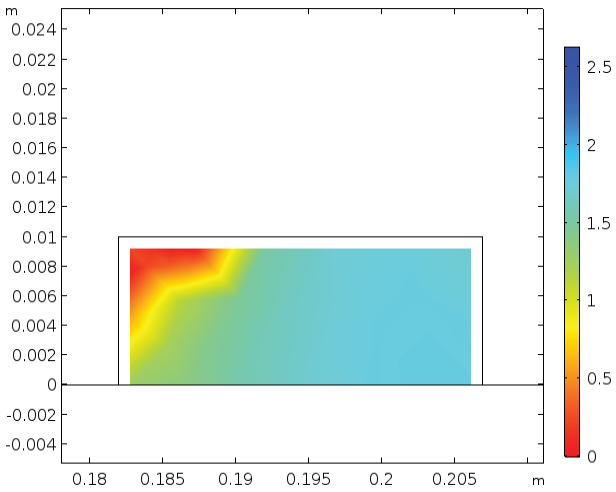

(d)

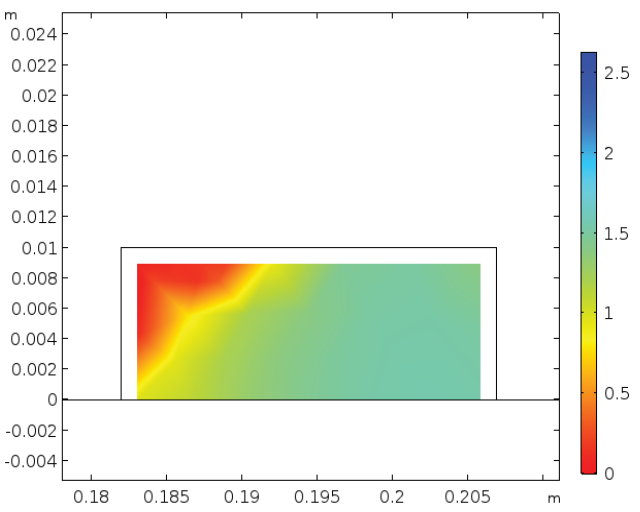

(e)

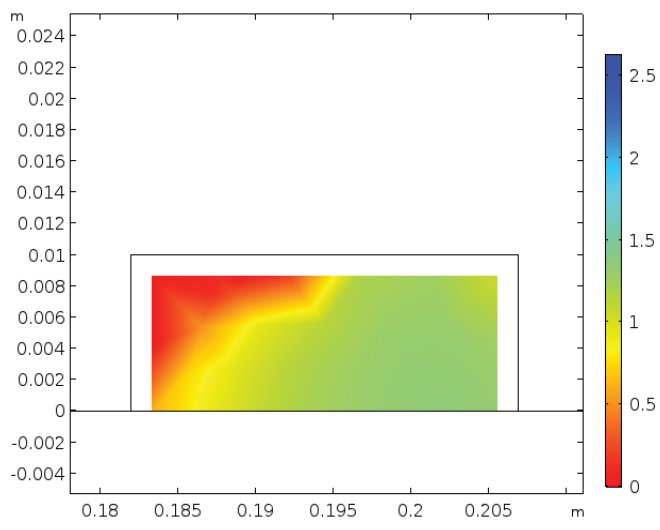

(f)

Figure 4- Evolution in the moisture content of the food over time during drying process considering the shrinkage effect (a, start of drying; $b$, first hour; c, second hour; $d$, third hour; e, fourth hour; f, fifth hour) (air temperature of $40^{\circ} \mathrm{C}$, air velocity of $0.5 \mathrm{~m} \mathrm{~s}^{-1}$ ) 


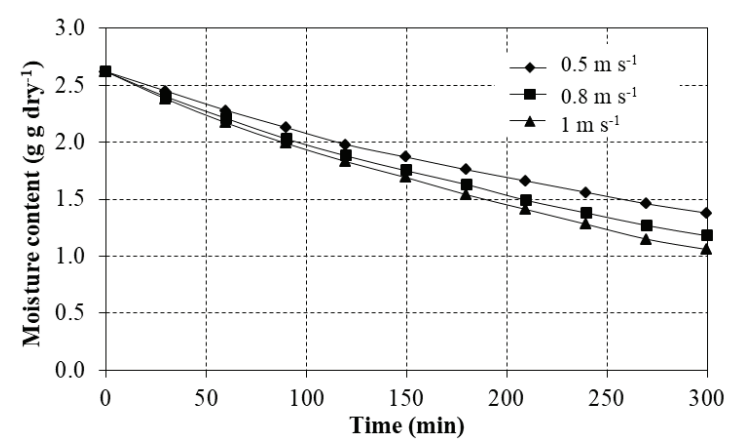

(a)

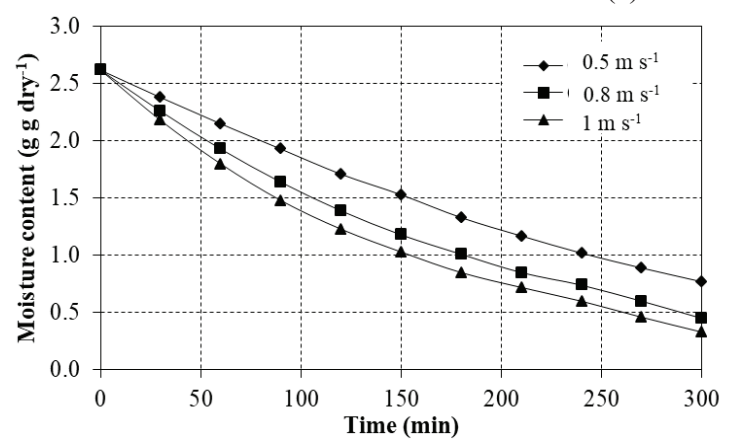

(b)

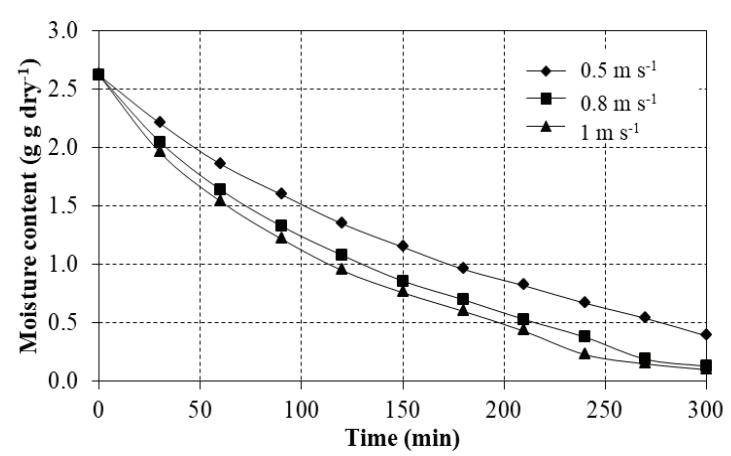

(c)

Figure 5- Moisture profiles of foods with different shapes at different air velocities at air temperature $40{ }^{\circ} \mathrm{C}$ (a, rectangle; b, cylinder; c, square)

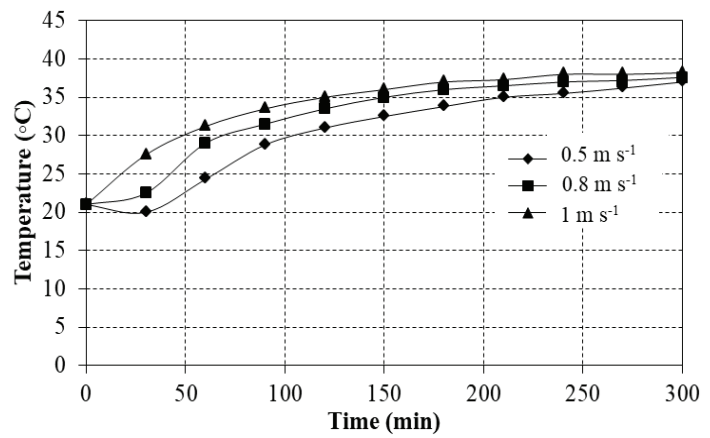

(a)

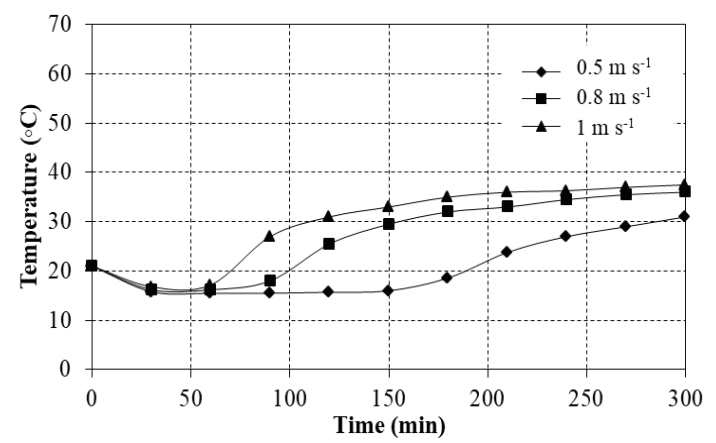

(b)

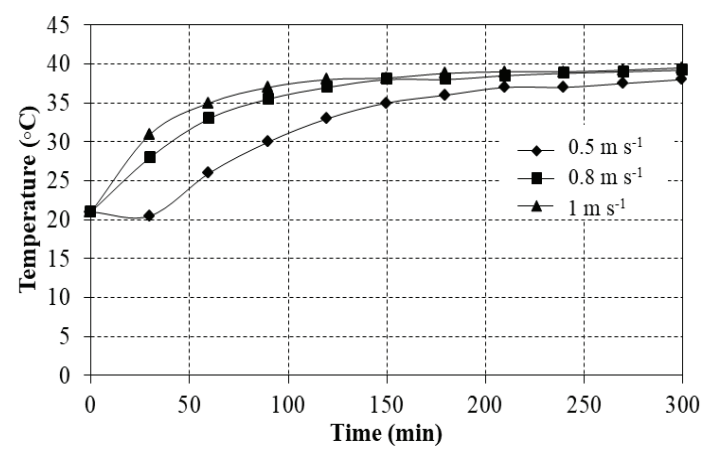

(c)

Figure 6- Surface temperature distributions obtained at different air velocities of foods with different geometric shapes at air temperature $40^{\circ} \mathrm{C}$ (a, rectangle; b, cylinder; c, square) 


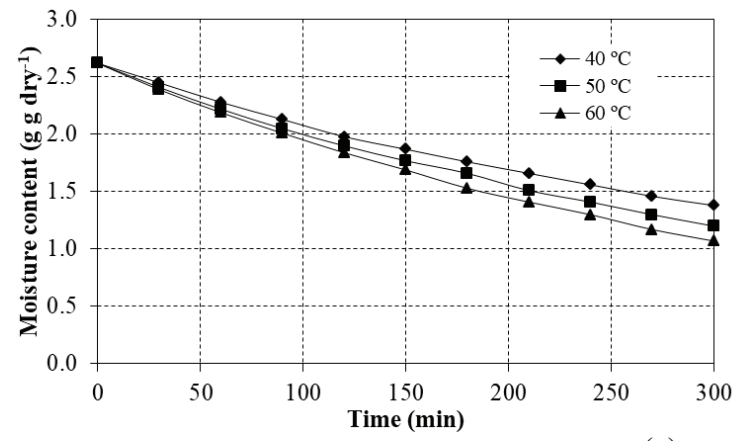

(a)

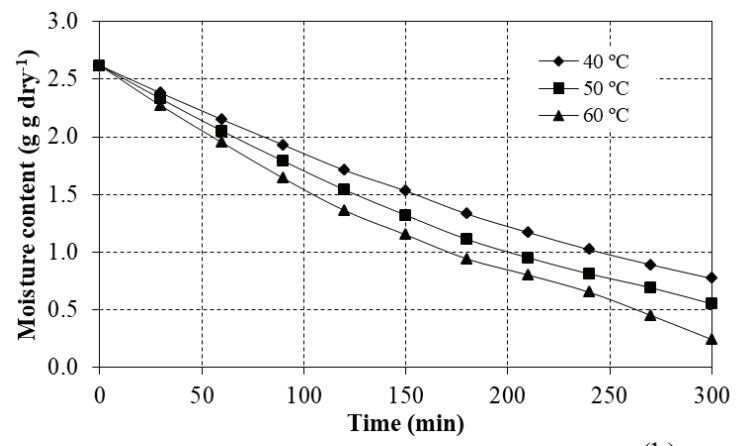

(b)

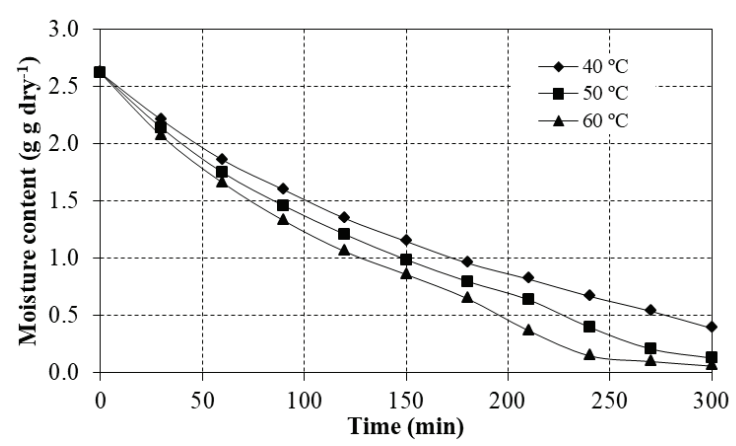

(c)

Figure 7- Moisture contents at different air temperatures of foods with different geometric shapes at air velocity $0.5 \mathrm{~m} \mathrm{~s}^{-1}$ (a, rectangle; b, cylinder; c, square)

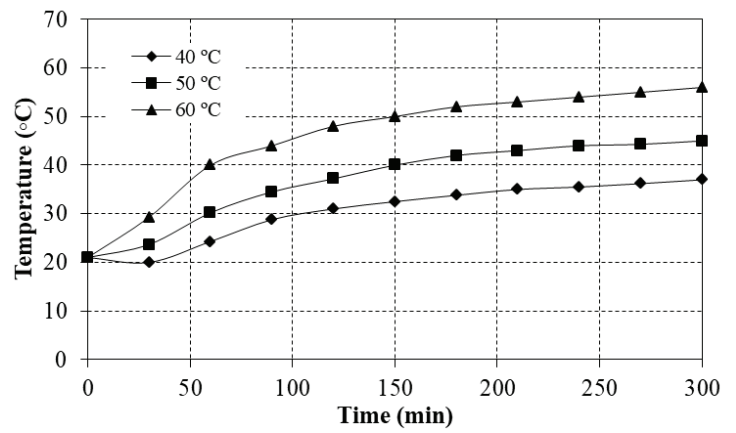

(a)

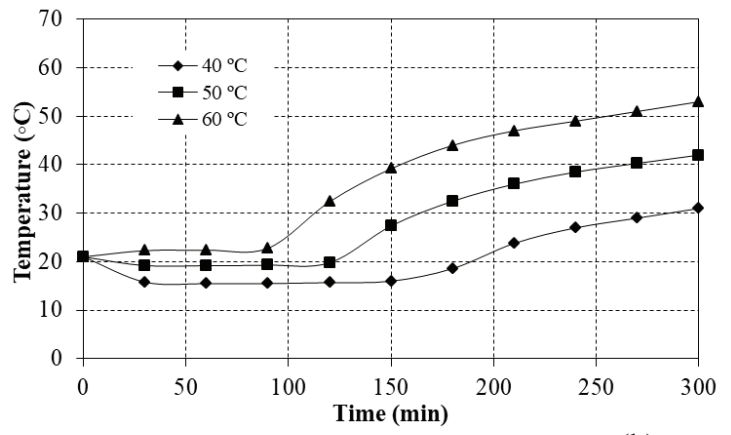

(b)

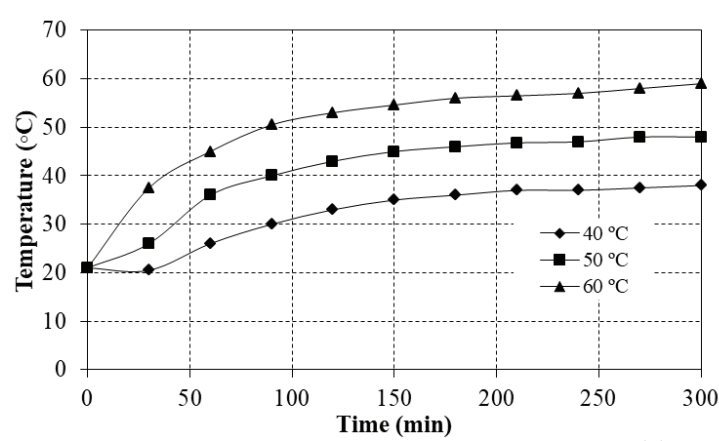

(c)

Figure 8- Surface temperature distributions at different air temperatures of foods with different geometric shapes at air velocity $0.5 \mathrm{~m} \mathrm{~s}^{-1}$ (a, rectangle; b, cylinder; $c$, square) 
As the drying air temperature increased, the moisture content decreased and the drying time was shortened (Aversa et al 2007). The moisture content values of the rectangular, cylinder and square shape food at the drying air temperature of $60{ }^{\circ} \mathrm{C}$ at the end of the fifth hour, were calculated to be 1.07, 0.24 and $0.06 \mathrm{~g} \mathrm{~g} \mathrm{dry}^{-1}$, respectively. It was observed that the lowest moisture content among the geometric shapes was obtained from square shape food during the drying process at different air temperatures. 50\% increase of air temperature caused $97 \%$ decrease in moisture content of square-shaped food at the end of the fifth hour at $0.5 \mathrm{~m} \mathrm{~s}^{-1}$ air velocity. Surface temperatures at different drying air temperatures for rectangular, cylinder and square shapes food are shown in Figure 8. The surface temperature values increased over time as the air temperature increased. The surface temperature values of rectangular, cylinder and square shape food material were determined to be 56,53 and $59{ }^{\circ} \mathrm{C}$, respectively, after the five-hour period at the air temperature of $60{ }^{\circ} \mathrm{C}$. The highest temperature increase occurred in the square shape food. It is clear that increasing drying air velocity and temperature improved considerably drying rate. Similar moisture profiles were obtained by some studies in the literature (Karim \& Hawlader 2005; Nguyen \& Price 2007; Curcio et al 2008; Thuwapanichayanan et al 2011; Kumar et al 2015). Parametric analysis showed that the square shape food material had the fastest drying characteristic compared with the other food shapes. Evaporative cooling occurred at the beginning of the drying process in Figure 6 and 8. Temperature decrease was observed in the first 30 minutes of the drying of the food. The food surface initially covered with a moisture layer. The amount of moisture evaporated from the food was high at the first stage of the drying period compared to as shown in Figure 5, 6 and 7. At the beginning of the drying, the decreased temperature profile was also obtained in some studies in the literature including (Turner \& Jolly 1991; Zhang \& Mujumdar 1992; Curcio et al 2008; Golestani et al 2013; Kumar et al 2015). The increased temperature in the food may cause quality deterioration. Therefore, it is necessary to optimize the drying process to increase food quality. Thus, with intermittent drying, the process can be restarted after each temperature period, and more evaporation can be provided (Kumar et al 2015).

\section{Conclusions}

In this study, firstly, two different theoretical models with and without shrinkage effect were developed in order to define the drying characteristics (temperature and moisture distributions). The numerical results obtained from these two theoretical models were compared with the obtained experimental results. The numerical results of both theoretical models were found to be in considerable agreement with experimental results. Furthermore, a parametric analysis was carried out to investigate the surface temperature and moisture content of the foodstuff for different air velocity $(0.5,0.8$ and $\left.1 \mathrm{~m} \mathrm{~s}^{-1}\right)$ temperature $\left(40,50\right.$ and $\left.60{ }^{\circ} \mathrm{C}\right)$ and different geometric shapes. The conclusions can be summarized as follows:

According to the obtained results it was determined that the fastest drying occurred in the square shape food at the air temperature of $60^{\circ} \mathrm{C}$ and the air velocity of $0.5 \mathrm{~m} \mathrm{~s}^{-1}$. Therefore, the square slice can be preferred to carry out a faster-drying process. It was shown that the moisture content of rectangular shape food at the end of the fifth hour was higher than other cylinder and square shapes food. Temperature values obtained for cylindrical shape food at the air temperature of $40{ }^{\circ} \mathrm{C}$ and the air velocity of $0.5 \mathrm{~m} \mathrm{~s}^{-1}$ in the first 150 minutes of the drying were constant and under $20{ }^{\circ} \mathrm{C}$. Cylindrical shape food should be used to achieve more evaporation at low surface temperatures. As expected, it was observed that the increased air velocity and temperature on drying decreased the drying time. The analysis result showed that the air velocity and temperature are important parameters on the evaporating moisture content. The remaining moisture content may cause food deterioration and microorganism activity. For this reason, minimizing the moisture content is vital. It is difficult to determine how much moisture remains at any point in the food during drying, experimentally. Therefore, numerical analysis of drying process is 
very important. By using the numerical method, the temperature and moisture distributions of the food can be easily estimated depending on the time. For three geometric forms (rectangle, cylindrical and square) it was shown that when the temperature and velocity of air $40{ }^{\circ} \mathrm{C}$ and $0.5 \mathrm{~m} \mathrm{~s}^{-1}$, respectively, in the first 30 minutes of the temperature of the food was decreased slightly. This situation was occurred due to the evaporative cooling phenomenon during the initial stages of drying. Thus keeping the product temperature in low level is important for the quality of the food. Finally, the drying period should be optimized by using numerical method. The developed numerical model should be also used for three-dimensional geometries in future drying research.

\section{References}

Ateeque M, Udayraj, Mishra R K, Chandramohan V P \& Talukdar P (2014). Numerical modeling of convective drying of food with spatially dependent transfer coefficient in a turbulent flow field. International Journal of Thermal Sciences 78:145-157

Aversa M, Curcio S, Calabro V \& Iorio G (2007). An analysis of the transport phenomena occurring during food drying process. Journal of Food Engineering 78(3): 922-932

Bart-Plange A, Addo A, Ofori H \& Asare V (2012). Thermal properties of gros michel banana grown in Ghana. ARPN Journal of Engineering and Applied Sciences 7(4): 478-484

Bird R B, Stewart W E \& Lightfoot E N (1960). Transport Phenomena. John Wiley \& Sons, London, UK

Comsol Multiphysics 5.3 (2017). Heat Transfer Model Library, Heat Transfer Module User's Guide, Chemical Reaction Engineering Module User's Guide

Curcio S, Aversa M, Calabro V \& Iorio G (2008). Simulation of food drying: FEM analysis and experimental validation. Journal of Food Engineering 87: $541-553$

Datta A K (2007a). Porous media approaches to studying simultaneous heat and mass transfer in food processes. I: Problem formulations. Journal of Food Engineering 80(1): $80-95$

Datta A K (2007b). Porous media approaches to studying simultaneous heat and mass transfer in food processes.
II: Property data and representative results. Journal of Food Engineering 80(1): 96-110

Defraeye T, Nicolai B, Mannes D, Aregawi W, Verboven P \& Derome D (2016). Probing inside fruit slices during convective drying by quantitative neutron imaging. Journal of Food Engineering 178: 198-202

Desmorieux H \& Moyne C (1992). Analysis of dryer performance for tropical foodstuffs using the characteristic drying curve concept, in Drying, A.S. Mujumder, Editor, pp. 834-843

Golestani R, Raisi A \& Aroujalian A (2013). Mathematical modelling on air drying of apples considering shrinkage and variable diffusion coefficient. Drying Technology 31(1): 40-51

Hussain M M \& Dincer I (2003). Numerical simulation of two-dimensional heat and moisture transfer during drying of a rectangular object. Numerical Heat Transfer, Part A: Application: An International Journal of Computation and Methodology 43(8): 867878

Karim M A \& Hawlader M N A (2005). Mathematical modelling and experimental investigation of tropical fruits drying. International Journal of Heat and Mass Transfer 48(23): 4914-4925

Kumar C, Millar G J \& Karim M A (2015). Effective diffusivity and evaporative cooling in convective drying of food material. Drying Technology 33(2): 227-237

Lima A G B, Queiroz M R \& Nebra S A (2002). Simultaneous moisture transport and shrinkage during drying solids with ellipsoidal configuration. Chemical Engineering Journal 86(1-2): 85-93

Liu J Y \& Cheng S (1991). Solutions of Luikov equations of heat and mass transfer in capillary porous bodies. International Journal of Heat and Mass Transfer 34(7): 1747-1754

Machado M D, Oliviera F A R, Gekas V \& Singh R P (1998). Kinetics of moisture uptake and solublesolids loss by puffed breakfast cereals immersed in water. International Journal of Food Science and Technology 33(3): 225-237

Nguyen H M \& Price E W (2007). Air drying of banana: Influence of experimental parameters, slab thickness, banana maturity and harvesting season. Journal of Food Engineering 79(1): 200-207

Ruhanian S \& Movagharnejad K (2016). Mathematical modelling and experimental analysis of potato thin-layer drying in an infrared-convective dryer 
engineering in agriculture. Environment and Food 9(1): 84-91

Sabarez H T (2012). Computational modelling of the transport phenomena occurring during convective drying of prunes. Journal of Food Engineering 111(2): 279-288

Sanjuan N, Simal S, Bon J \& Mulet A (1999). Modelling of broccoli stems rehydration process. Journal of Food Engineering 42(1): 27-31

Thuwapanichayanan R, Prachayawarakorn S, Kunwisawa J \& Soponronnarit S (2011). Determination of effective moisture diffusivity and assessment of quality attributes of banana slices during drying. LWT-Food Science and Technology 44(6): 1502-1510
Turner I W \& Jolly P C (1991). Combined microwave and convective drying of a porous material. Drying Technology 9(5): 1209-1269

Welty J, Wicks C, Wilson R \& Rorrer G (2001). Fundamentals of Momentum. Heat, and Mass Transfer, New York: John Wiley and Sons

Yan Z, Sousa-Gallagher M J \& Oliveira F A R (2008). Shrinkage and porosity of banana, pineapple and mango slices during air-drying. Journal of Food Engineering 84: 430-440

Zhang W \& Mujumdar A S (1992). Deformation and stress analysis of porous capillary bodies during intermittent volumetric thermal drying. Drying Technology 10(2): 421-443 